\title{
Causal Legal Semantics: A Critical Assessment*
}

\author{
Brian Flanagan \\ School of Law, National University of Ireland, Maynooth \\ brian.flanagan@nuim.ie
}

\begin{abstract}
A provision's legal meaning is thought by many to be a function of its literal meaning. To explain the appearance that lawyers are arguing over a provision's legal meaning and not just over which outcome would be more prudent or morally preferable, some legal literalists claim that a provision's literal meaning may be causally, rather than conventionally, determined. I argue, first, that the proposed explanation is inconsistent with common intuitions about legal meaning; second, that explaining legal disagreement as a function of the causally determined meanings of moral terms requires, but lacks, a causal semantics which is clearly consistent with the scope of moral disagreement. Finally, I suggest that an element of the theory of language invoked by 'causal' legal literalists might be better deployed as part of an intentionalist account of legal practice.
\end{abstract}

\section{Keywords}

legal disagreement, causal theory of reference, legal intentionalism

Legal theorists seek, among other things, to explain the structure of our practice of statutory interpretation. Many believe that a statute's legal meaning is a function of its literal meaning, that is, of the various meanings conventionally attributed to the terms adopted. ${ }^{1}$ On this hypothesis,

* I would like to thank Leslie Green, Gerard Casey, Maria Baghramian, John O'Dowd and Donal Coffey for their comments on earlier versions of this paper.

1 '[T] he general words we use - like "vehicle" in the case I consider - must have some standard instance in which no doubts are felt about its application. There must be a core of settled meaning, but there will be, as well, a penumbra of debatable cases in which words are neither obviously applicable nor obviously ruled out ... in applying legal rules, someone must take the responsibility of deciding that words do or do not cover some case in hand with all the practical consequences involved in this decision.' HLA Hart, 'Positivism and the Separation of Law and Morals', Harvard Law Review 71 (1958), pp. 593-629, 607. Some theorists hold that legal meaning is just a function of literal meaning, e.g., John Manning, 'The Absurdity Doctrine', Harvard Law Review 116 (2003), pp. 2387-2486, 2391, '[R]espect for the legislative process requires judges to adhere to the precise terms of statutory texts' and 
collective adherence to the statute book's literal meaning is what accounts, in part anyway, for the striking agreement on the content of the law - the countless 'easy cases'. Just as importantly, adherence to statutes' literal meaning is consistent with the possibility of disagreement about the resolution of a case. Thus, just as an utterance's literal meaning may be indeterminate, so may a statute's legal meaning. When it is, disagreement can be expected over the morality and prudence of alternative legal outcomes. Legal literalism thus promises to steer a steady course between the 'nightmare' that judges are just legislators in robes, and the 'noble dream' that judicial disagreements simply concern the law as it is. ${ }^{2}$

A persistent criticism of legal literalism is that it fails to account for judicial disagreements which do concern the law as it is. If the legal meaning of a statute consists in the conventional meanings of its words, and interpreters are familiar with its words and their conventional meanings, how do we explain the appearance that they are arguing over its legal meaning and not just over which outcome would be more prudent or morally preferable? In light of this criticism, some have proposed a very different sort of legal literalism, one better equipped to explain the scope of legal disagreement. These theorists continue to claim that a provision's legal meaning is a function of the meanings of its terms, but add that those meanings are often causally, rather than conventionally, determined. We shall call this 'causal legal semantics'.

precludes them 'from making ad hoc exceptions to generally worded laws'; Aileen Kavanagh, 'Original Intention, Enacted Text and Constitutional Interpretation', American Journal of Jurisprudence 47 (2009), pp. 255-98, 275, '[T] tained in the Constitution... must be contained in the text of the Constitution..' Others hold that legal meaning is a function of both literal meaning and the purposes for which the statute was obviously enacted, a position which Hart himself adopted in response to Lon Fuller's famous reply to his $195^{8}$ article: ' $[A]$ legal system often has other resources besides the words used in the formulations of its rules which serve to determine their content or meaning in particular cases. Thus... the obvious or agreed purpose of a rule may ... serve to show that words in the context of a legal rule may have a meaning different from that which they have in other contexts.' Hart, Essays in Jurisprudence and Philosophy (Oxford: Clarendon Press, 1983), p. 8. See similarly, Wil Waluchow, 'Defeasibility and Legal Positivism', in J Ferrer et al. (eds), Essays on Legal Defeasibility (Oxford University Press, forthcoming); Aharon Barak, Purposive Interpretation (Princeton: Princeton University Press, 2005), p. 8o; Kent Greenawalt, 'The Nature of Rules and the Meaning of Meaning' Notre Dame Law Review 72 (1998), pp. 1449-74, 1472-3; Antonin Scalia, A Matter of Interpretation (Princeton: Princeton University Press, 1997) pp. 20-21.

${ }^{2}$ HLA Hart, 'American Jurisprudence through English Eyes: The Nightmare and the Noble Dream', Georgia Law Review 11 (1976), pp. 969-89. 
I argue, first, that causal legal semantics cannot account for common intuitions about legal meaning; second, that explaining legal disagreement as a function of the causally determined meanings of moral terms requires, but lacks, a causal semantics which is clearly consistent with the scope of moral disagreement. Having developed these criticisms, I suggest that an element of the theory of language invoked by the new legal semantics might be better deployed as part of a traditional intentionalist account of legal practice.

\section{The New Semantic Strategy}

The explanatory value to legal theory of the causal theory of reference standardly attributed to Saul Kripke ${ }^{3}$ has been defended in progressively greater detail by Michael Moore, ${ }^{4}$ David Brink ${ }^{5}$ and Nicos Stavropoulos. ${ }^{6}$ Scott Soames, noted for his defence of an expansive reading of Kripke's work, ${ }^{7}$ has recently offered his own account of legal interpretation. ${ }^{8}$ Significantly, Soames accepts the possible legal relevance of Kripkean semantics. ${ }^{9}$ It is therefore timely to reassess the value of causal semantics for legal theory.

The causal theory of reference (CTR) states that a term's reference is not determined by conventionally associated criteria or practices of usage but by an act of baptism: term $t$ refers to just whatever is in fact the same object

3 Kripke's 1970 Princeton lectures were first published as 'Naming and Necessity', in Donald Davidson \& Gilbert Harman (eds.), Semantics of Natural Language (Dordrecht: Reidel, 1972) pp. 253-355.

4 Moore, 'A Natural Law Theory of Legal Interpretation', Southern Califormia Law Review $5^{8}$ (1985), pp. 277-398; Moore, Educating Oneself In Public (Oxford: Oxford University Press, 2000) pp. 100-04, 337-54.

5 E.g., Brink, 'Legal Theory, Legal Interpretation, and Judicial Review', Philosophy and Public Affairs 17 (1988) 105-48; Brink, 'Legal Interpretation, Objectivity, and Morality', in Brian Leiter (ed.), Objectivity in Law and Morals (Cambridge: Cambridge University Press, 2001) pp. $12-65$.

6 Stavropoulos, Objectivity in Law (Oxford: Oxford University Press, 1996).

7 E.g., Soames, Reference and Description: The Case against Two-Dimensionalism (Princeton: Princeton University Press, 2005).

8 Soames, 'Interpreting Legal Texts: What Is, and What Is Not, Special about the Law', in Soames, Natural Language: What It Means and How We Use It (Princeton: Princeton University Press, 2009) pp. 403-24.

9 As does Michael Devitt; '[Conventionalist semantics] places far too heavy an epistemic burden on competent users of these words [including socio-legal words like "contract"] ... None of these problems arise for the causal theory.' Devitt, 'Deference and the Use Theory', ProtoSociology 27 (2011) pp. 196-211, 205. 
or kind as that baptized as ' $t$ '. Soames describes CTR's application to natural kind terms (terms such as 'water' and 'tiger') thus:

[A natural kind term's] meaning is the kind it names, and its reference is determined by agreed upon instances, plus a special similarity relation, holding between instances of the kind, the specific content of which needn't be known, even by competent speakers. ${ }^{10}$

Seminal work by Kripke, Keith Donnellan ${ }^{11}$ and Hilary Putnam ${ }^{12}$ has suggested to many philosophers that, at least with respect to proper names and natural kind terms, CTR fits our linguistic intuitions better than theories which claim that reference is determined by usage or associated descriptions. Admittedly, even with respect to such kinds of terms, CTR faces a variety of complications. ${ }^{13}$ We overlook those issues here; causal legal semantics faces special difficulties.

The major attraction of CTR for legal theorists is its potential to explain the scope of legal disagreement. ${ }^{14}$ Applying CTR to the interpretation of a statutory provision, it follows that $X$ is subject to the provision if and only if $X$ is relevantly similar to agreed upon instances of a kind denoted by a term with which the provision is written. As the content of the similarity relation

10 Soames, Natural Language: What It Means and How We Use It p. 406. Moore offers a non-canonical understanding of CTR, according to which, baptizers' paradigms need not be instances of the kind baptized: ' $[\mathrm{P}]$ aradigms may turn out not to be instances of the kind at all ... [T] he baptizers need [only] have before them puzzlingly similar particulars from which they self-consciously hypothesize a kind ...' Moore, 'Can Objectivity be Grounded in Semantics?', in Enrique Villanueva (ed.), Law: Metaphysics, Meaning, and Objectivity (Amsterdam: Rodopi Philosophical Studies, 2007) pp. 235-62, 254-56. It is unclear how the existence of a kind may be hypothesized from particulars none of which need be an instance of the kind. It is equally unclear how one might measure progress toward uncovering the relevant similarity relation.

11 Donnellan, 'Proper Names and Identifying Descriptions', Synthese 21 (1970), pp. 335-58.

12 Putnam, 'The Meaning of Meaning', in K. Gundersen, (ed.) Language, Mind and Knowledge (Minnesota: University of Minnesota, 1975), pp. 131-93.

13 Such as how exactly to account for reference change; Gareth Evans, "The Causal Theory of Names', Aristotelian Society Supplementary 47 (1973) 187-225; how a single kind is isolated in baptism; John Dupré, 'Natural Kinds and Biological Taxa', Philosophical Review 9o (1981) pp. 66-9o; and the possible absence of a common element in the causal production of a range of features belonging to a set of samples; Kyle Stanford \& Philip Kitcher, 'Refining the Causal Theory of Reference for Natural Kind Terms' Philosophical Studies 97 (2000) pp. 99-129.

14 See Stavropoulos, Objectivity in Law, p. 5. See also, Ronald Dworkin, 'Hart's Postscript and the Character of Political Philosophy', Oxford Journal of Legal Studies 24 (2004) pp. 1-37, 11-13 (but see Dworkin, Justice in Robes (Cambridge, Mass: Harvard University Press, 2006) 11-12 and Brian Bix, 'Global Error and Legal Truth', Oxford Journal of Legal Studies 29 (2009) pp. 535-47, 545-47). 
holding between agreed upon instances of the denoted kind may be misunderstood, the fact that a statutory term conventionally refers to $X$ is neither necessary nor sufficient for $X$ to count as legal (or illegal).15 Accordingly, disagreement over a provision's legal meaning may be expected even among interpreters familiar with its terms' conventional meanings.

Some legal disagreements concern the implications of statutes written in moral language, statutes regulating that which is 'due' or 'cruel'. Moore et al. explain such disagreement as a product of the interpretive effort to establish the causally determined meanings of these terms. For instance, the Eighth Amendment to the US Constitution prohibits the imposition of 'cruel and unusual' punishments. If the Amendment's legal meaning depends on the reference of the term, 'cruel', and the latter is a function of a similarity relation whose content may be unknown, then whether the Amendment prohibits, say, capital punishment, is something about which there could be meaningful disagreement. Should the authors of the Bill of Rights, or anyone else, misapprehend the content of the similarity relation holding between instances of the moral kind 'cruelty', they stand to be corrected, and with it their understanding of the Eighth Amendment.

We turn now to the first objection to the use of Kripkean semantics in legal theory: its inability to account for common intuitions about legal meaning.

\section{Literal Meaning as Legal Meaning}

The answers to most legal questions seem obvious. Some seem obvious even after apparent mistakes about the literal meaning of enacted terms have come to light. Stephen Munzer soon suggested that this phenomenon conflicts with causal legal semantics:

Once upon a time people began to be concerned about the overharvesting of the creatures of the sea. Accordingly, the legislature enacted a statute ... "No boat or vessel shall remove more than 20 tons of fish per year from the fishing areas described below.... It turns out that when the legislature passed the statute, it was universally believed that whales were fish ... A committee report

15 Paraphrasing Geoffrey Sayre-McCord, 'Different Kinds of Kind Terms', Philosophical Issues 8 (1997), pp. 313-23, 317. 
on the statute indicates that the legislature was concerned about the ... overharvesting of fish, including ... whales. ${ }^{16}$

We are invited to agree that, intuitively, the taking of more than 20 tons of whale in a given year is illegal. Yet whales are mammals, not fish. Arguably, CTR has a good story to tell of how we once thought that the term 'fish' referred to whales and now do not - something about how, having improved our understanding of the shared nature of certain paradigm 'fish', we came to realize that their nature is not shared by whales. That story is clearly unavailable to explain our intuitive interpretation of the statute, since, notwithstanding our improved comprehension of the reference of 'fish', we still think that it regulates whaling. But then, if outcomes known to be entailed by a provision's literal meaning may be counter-intuitive, a simple explanation of legal meaning as literal meaning is equally unavailable. Munzer thus presents a critical challenge to causal legal semantics. ${ }^{17}$ Three ways of meeting it have been suggested. We assess each in turn.

\section{Literal Meaning as a Weighted Contribution to Legal Meaning}

One response to Munzer's hypothetical is to claim that we treat an enactment's literal meaning as but one, out-weighable component of its legal meaning. Thus, Brink and Moore suggest that a statute's legal meaning also depends, in part, on its purpose. Due attention to legislative purpose might demand a legal outcome other than that which is literally entailed. Brink concludes, 'since appeal to underlying purpose can override semantic content, if these conflict, my interpretive view allows the interpretive conclusion that [whaling is indeed regulated] ${ }^{18}$ In the event of conflict, Brink

16 Stephen Munzer, 'Realistic Limits on Realist Interpretation' Southern California Law Review 58 (1985) pp. 459-75, 469 .

17 A challenge readily reconstructed on historical premises: 'A tenth branch of the King's ordinary revenue, said to be grounded on the consideration of his guarding and protecting of the seas from pirates and robbers, is the right to royal fish, which are whale and sturgeon: and these, whether either thrown ashore, or caught near the coasts, are the property of the King ... [This right] is expressly claimed and allowed in the statute de praerogativa regis [17 Edw. II Ch. Il (1325)].' William Blackstone, Commentaries on the Laws of England (Oxford: Oxford University Press, 1765), Book 1 Ch 8 para 10 (emphasis added). I am grateful to Donal Coffey for bringing this provision to my attention.

18 D Brink, 'Semantic and Legal Interpretation (Further Thoughts)', Canadian Journal of Law \& Jurisprudence 2 (1989) pp. 181-91, 186; similarly, Brink, 'Legal Interpretation, Objectivity and Morality' pp. 25-26, 60 n 39; Moore, 'A Natural Law Theory of Legal 
suggests choosing the legal outcome most coherent with, 'existing legal principles, constitutional provisions, statutes, and precedents' ${ }^{19}$

Brink's suggested resolution of potential conflicts would require interpreters to know the legal meaning of 'existing constitutional provisions, statutes', etc. If, however, a provision's legal meaning is a function of both its literal meaning and legislative purpose, the legal meaning of the statute book's other provisions is similarly a function of both their literal meanings and legislative purposes. Until we know how to resolve conflicts between these factors, we will be unable to attribute legal meanings to the system's other provisions in order that we may discern the legal outcome most coherent therewith. Referring the interpreter to the legal meanings of other provisions thus leaves him no closer to resolving conflict between a provision's legislative purpose and literal meaning. Yet, according to Munzer, interpreters have no problem deciding that whaling is regulated. Brink may present a causal legal semantics that is consistent with the intuitions Munzer reveals, but it is poorly placed to explain them.

On Moore's account, in contrast, the weight of literal meaning and legislative purpose is ultimately a moral matter, a function of the moral facts of the case.$^{20}$ Unfortunately, there is a suite of complications facing proposals to explain a provision's legal meaning by reference to conflicting factors of relative weight.

If the theorist offers a criterion according to which literal meaning, legislative purpose and, say, the moral facts, each carry preset weights in the determination of legal meaning, there is the distinct prospect of cases in which a provision's literal meaning ought to be decisive but in fact implies

Interpretation' $384-85$, 'A judge must check the provisional interpretation reached from these ingredients [semantic meaning] with an idea of how well such an interpretation serves the purpose of the rule in question ... Less ordinary meaning, or a more strained reading of statutory definitions and precedent, will be traded off against a better purpose'. Heidi Hurd's 'non-communicative' theory of legislation, according to which statutes are 'natural signs' of causally related empirical phenomena, appears to adopt a similar tack:

[A] non-communicative model of legislation would call upon courts to interpret a statute by seeking to discover and to achieve the optimal state of affairs of which the statute is a natural sign. This is no more than a long-winded way of saying the familiar: that courts should interpret statutes in light of the purposes that they may best be made to serve.

Hurd, 'Sovereignty in Silence' Yale Law Journal 99 (1990) pp. 945-1028, 1028.

19 Brink, 'Legal Theory, Legal Interpretation, and Judicial Review', p. 132 (referred to in Brink, 'Semantic and Legal Interpretation (Further Thoughts)', p. 188); similarly, Brink, 'Legal Interpretation, Objectivity and Morality', pp. 33-34.

20 Moore, 'A Natural Law Theory of Legal Interpretation', pp. $387-88$. 
an outcome that seems legally incorrect. Thus, imagine a scenario in which Munzer's legislature sought to restrict whaling simply in order to oppress an ethnic minority for whom whaling was the primary livelihood. We would presumably agree that the 'fish' statute does indeed restrict whaling notwithstanding both its literal meaning and immoral character. Munzer's challenge would remain essentially unanswered.

In a similar vein, one might characterize some factor as a reserve determinant of legal meaning, to be used in the event of conflict between other determinants. In addition to the prospect of cases in which that factor ought to be decisive but in fact implies a counter-intuitive outcome, such a characterization would be at risk of seeming arbitrary; how could a factor determine a result notwithstanding a contrary indication from either literal meaning or legislative purpose but not have any impact where such factors are in agreement? Our legal intuitions are hardly so sensitive as to cease to respond to the reserve factor altogether in such an event. Very often a provision's literal meaning and legislative purpose entail the same outcome and all agree that it is obviously correct. On some such occasions the reserve factor will indicate a contrary result. When it does, we go from general agreement on its indications' correctness (the regulation of whaling under the original 'fish' statute), to thinking its indications obviously incorrect. This would seem a curiously sharp contrast in our response to a determinant of legal meaning.

The alternative is to posit that the weight of a determinant of legal meaning varies with the provision in question. This strategy avoids the problem of counter-intuitive legal outcomes but at considerable cost. If the weight of a supposed determinant varies from provision to provision, we will struggle to account for broad interpretive agreement in cases of conflict between determinants, such as that induced by the Munzer scenarios. How were interpreters to know what weights the determinants were to have so as to venture with such confidence what the correct interpretation should be? Conversely, for questions such as the constitutionality of the death penalty, the very sort of legal disagreement whose explanation is said to motivate causal legal semantics, how were interpreters to know that the weights were so finely balanced as to permit the occurrence of meaningful legal disagreement? Interpreters could hardly be said to be following past patterns. Should they in fact know how some past conflict was resolved, they must have some means of identifying correct interpretations which does not require attributing weights to specified factors. Identifying that means would provide a simpler explanation for the occurrence of both interpretive agreement and meaningful disagreement than a hypothesis 
which adds a role for a further set of factors. Preserving causal legal semantics from counterexamples by characterizing literal meaning as a codeterminant of varying weight strips the theory of its explanatory value. ${ }^{21}$

\section{Literal Meaning as Default Legal Meaning}

An alternative response to Munzer's challenge is to claim that a provision's literal meaning does not count towards its legal meaning should it be apparent that its terms were not intended literally. ${ }^{22}$ If, as in Munzer's hypothetical, it is obvious that the legislature intended to regulate a class of objects not denoted by its adopted terms, literal meaning is immaterial. Legally speaking, the statute refers as clearly intended. This response seems to deal well with the objection that what is legally obvious, e.g., the quota on whaling, may be counter-semantic. Consider Scott Soames' historical example:

The case turns on whether tomatoes count as vegetables rather than fruits, and so are subject to a tariff on vegetables that excludes fruits. The issue is whether the meaning of the word 'fruit' excludes all vegetables, while including the edible 'ripened seed-bearing ovary of the plant', as my dictionary puts it thereby precluding tomatoes ...23

Soames considers how one might answer the legal question if the word, "fruit", like other natural kind terms, had only a single "scientific" meaning, ${ }^{24}$ i.e., if its literal meaning just denoted the edible, ripened, seed-bearing ovary of the plant:

On this hypothesis, the literal meaning of the statutory language excludes tomatoes from the tax. Nevertheless ... [t] lawmakers asserted and committed themselves to, in adopting the statutory language. If, as seems plausible, they were using the terms 'fruit' and 'vegetable' referentially - on analogy with referential uses of descriptions - then they

21 The same applies to conventionalist legal literalism; see Brian Flanagan, 'Revisiting the Contribution of Literal Meaning to Legal Meaning, Oxford Journal of Legal Studies 30 (2010) pp. 255-71, 260, 267-69.

22 See Walter Sinnott-Armstrong, 'Word Meaning in Legal Interpretation', San Diego Law Review 42 (2005) pp. 465-92, 486, 'Word meaning might even still be primary in the sense that laws should be interpreted by their common word meanings ... except when ... it should be clear to all or most citizens that the legislators did not intend the literal word meaning.'

23 Soames, Natural Language: What It Means and How We Use It p. 407.

24 Soames, Natural Language: What It Means and How We Use It p. 408. 
thereby asserted, among other things, that tomatoes, cucumbers, and peas are subject to the tax, even if they misdescribed them. ${ }^{25}$

Since it is obvious that the legislature intended to tax tomatoes, it is clear why we agree that tomatoes are subject to the tax. Conversely, legal disagreements may still be explained as the product of interpretive efforts to establish a provision's literal meaning. Thus, if literal meaning is default legal meaning, then, absent a clear intention to the contrary, a provision regulating the hunting of 'tigers' applies to just those creatures holding the particular similarity relation shared by agreed upon instances of the term 'tiger'. Conceivably, a dispute could emerge as to whether some animal is regulated by the provision notwithstanding its failure to possess a set of characteristics conventionally associated with tigerhood. Whereas conventionalist legal literalism would struggle to account for this possibility, the causal theory would not - given the potential opacity of the relevant similarity relation, the criteria conventionally associated with tigerhood may be mistaken.

Nevertheless, some disputes remain mysterious. If a provision legally applies to a counter-semantic class of object (such as tomatoes or whales) only where, 'it is clear to all', that legislators intended the regulation of that class of object, it follows that whether a statute regulates objects other than those it literally denotes is not a subject for disagreement. ${ }^{26}$ Thus, if the only objects to which a legislature may non-obviously refer are those literally denoted by the terms in which its statute is written, disagreement over whether the statute regulates objects its terms clearly do not denote seems impossible.

In Munzer's statute, the term 'fish' was obviously used to refer to whales. But this might be only part of the story. Munzer's legislators may have intended the term to refer to an alternative natural kind, say, marine animals. ${ }^{27}$ Membership of this kind would seem a matter of natural fact,

25 Soames, Natural Language: What It Means and How We Use It p. 410.

26 Soames, Natural Language: What It Means and How We Use It p. 409. Notwithstanding a fleeting reference to the necessary transparency of counter-semantic intentions (in discussing the referential use of Donnellan's description, 'the man in the corner drinking champagne is a famous philosopher'), Soames is more fairly characterized as holding that legal meaning is a function of legislative intentions simpliciter; '[T] he content of the law includes everything asserted and conveyed in adopting the relevant legal texts.' Id 408-og (emphasis in original).

${ }_{27}$ ' $[T]$ o say that there can be no principled exclusion of whales is to say that the issue is not about what it is to be a fish. The mistaken theory of fish-hood prevalent when the statute was drafted explains why the word 'fish' was mistakenly used to pick out marine life. Again, 
something about which people may be generally ignorant or mistaken. If Munzer's legislators intended to regulate just the harvesting of such creatures, we might favour a reading of the statute according to which a species is protected just in case it is an animal kind adapted to marine life, regardless of whether legislators or initial interpreters had thought it such. Nineteenth century officials might well have mistaken coral and sea anemone for plant rather than animal life, and hence as outside the scope of the provision. Yet subsequent interpreters might claim the legislative quota had in fact always been applicable to those species. It would seem that a provision might thus carry a counter-semantic, yet nevertheless 'scientific', legal meaning.

Consider an actual example: the First Amendment to the US Constitution states that 'Congress shall make no law ... abridging the freedom of speech ....28 The Amendment's literal meaning implies that everyone capable of speech enjoys protection from Congress. The implication is at odds with the Amendment's accepted legal meaning. For instance, suspected enemy combatants held in Guantanamo Bay are excluded from First Amendment protection, ${ }^{29}$ and non-citizen residents can be deported for speech that would be protected had they been citizens..$^{30}$ Insofar as Congress may constitutionally limit the speech of certain speakers, the class of individuals protected by the Amendment is counter-semantic. Yet disagreement as to the identity of that (counter-semantic) class is currently raging through American law reviews. Take the question of whether only the political speech of natural persons qualifies for protection.

In the opinions accompanying the US Supreme Court's recent 5:4 ruling that campaign finance regulation violates corporations' and unions' constitutional right to political speech, the question of whether natural personhood is a necessary condition for such First Amendment protection was central. ${ }^{31}$ The ensuing controversy did not arise from a misunderstanding

"fish" in the statute does not stand for a special legal concept somewhat like, yet different than, fish. Rather, "fish" stands for marine life or something to that effect.' Stavropoulos, Objectivity in Law p. 192.

28 (Emphasis added).

29 http://www1.voanews.com/english/news/middle-east/US-Military-Panel-Hears-1st --Guantanamo-Appeal-82696517.html (accessed 21 December, 2010).

${ }^{30}$ See Harisiades v. Shaughnessy 342 US 580 (1952).

31 Citizens United v. FEC $55^{8}$ US _ (2010), 'By taking the right to speak from some and giving it to others, the Government [hereby] deprives the disadvantaged person or class of the right to use speech to strive to establish worth, standing, and respect for the speaker's voice ... [The] political speech of corporations or other associations should [not] be treated 
of the Amendment's literal meaning, and seemed distinctively legal, rather than merely moral or policy-based. Yet the existence of the controversy is mysterious if the Amendment's legal application departs from its literal meaning only in cases where its intended meaning is, 'clear to all'. The First Amendment's literal meaning implies that political speakers are protected. But the question, 'who is a political speaker', is not what Justices argued over in their debate on campaign finance regulation; the issue, rather, was whether the class of protected political speaker was limited to natural political speakers. If the legal meaning of the Amendment is opaque on this point, the opacity is not a function of its literal meaning - it being agreed that corporations and unions are political speakers.

Treating literal meaning as default legal meaning seems likely to produce outcomes which correspond with our intuitions as to what is obviously legally the case (e.g., whaling quotas, even those racially motivated), while allowing for the meaningfulness of disagreements concerning the nature of a kind literally denoted by statutory language. But the qualification appears inconsistent with the scope of legal disagreement. It seems to overlook the possibility of meaningful disagreement over the application of statutes to entities which all agree are, or all agree are not, literally denoted by their terms. Our example of the latter concerned the possible application of Munzer's 'fish' statute to the harvesting of sea anemone and coral; the contemporary disagreement over the protection of corporate speakers from laws abridging political 'speech' is an example of the former. Characterizing literal meaning as default legal meaning thus ignores a salient aspect of our legal practice - that aspect with which advocates of causal legal semantics are most concerned.

\section{As a Creation of Legislators}

Nicos Stavropoulos offers the most detailed elaboration of the application of CTR to legal interpretation. Taking 'concept-words' such as 'vehicle' and

\footnotetext{
differently under the First Amendment simply because such associations are not "natural persons." (Opinion of the Court, emphasis added); 'The conceit that corporations must be treated identically to natural persons in the political sphere is not only inaccurate but also inadequate to justify the Court's disposition of this case ... The fact that corporations are different from human beings might seem to need no elaboration, except that the majority opinion almost completely elides it.' (Stevens J, joined by Breyer, Ginsburg and Sotomayor JJ).
} 
'cruelty' as, 'the key semantic unit,', 32 tavropoulos defends a 'Kripke-Putnam semantics for law' ${ }^{33}$ Kripke-Putnam semantics is said to, 'determine[] the extension, or range of application' of legal concepts, ${ }^{34}$ thereby explaining the possibility of meaningful legal disagreement as the product of the interpretive effort to establish the statute's causally determined literal meaning. ${ }^{35}$ Earlier we noted Stavropoulos' observation that legislators might use a term such as 'fish' intending to refer to a natural kind other than fish. Stavropoulos reconciles this possibility with his initial claim that a provision's semantic properties determine its legal application by characterizing legislators as themselves Kripkean baptizers:

The best explanation, then, of legal practice shows that lawyers treat legal properties as genuine properties over which not only lawyers in general but the original 'reference-fixers' (the legislators) may be in substantive error. ${ }^{36}$

Presumably, Munzer's notional legislators had certain creatures in mind for their quota. On Stavropoulos' approach, the legal meaning of their statute is a function of the reference of its terms, where the latter is determined by the similarity relation in fact holding between legislators' paradigms, the content of which may be unknown. The literal reference of 'fish', as used in the statute, is fixed on whatever shares the nature of legislators' paradigms, which include, in this case, whale. ${ }^{37}$ If the statute's literal meaning determines its legal application, then, given Stavropoulos' understanding of its literal meaning, it should be both uncontroversial that it regulates whaling and potentially controversial that it regulates the taking of, say, sea anemone.

Treating legislators as Kripkean baptizers is costly on two fronts, however. The notion of legislative enactment as an act of linguistic baptism or reference-fixing is sharply at odds with our ordinary understanding; enactors do not view themselves in the role of baptizers, nor does the public or legal community generally. Certainly, some legal norms become named after the titles of statutory provisions, e.g., 'Section 4 Rape'. But, in such cases, the name has just become shorthand for the legal norm; no one

\footnotetext{
32 Stavropoulos Objectivity in Law p. 1.

33 Stavropoulos Objectivity in Law p. 4.

34 Stavropoulos Objectivity in Law p. 2.

35 Stavropoulos Objectivity in Law p. 4-5.

36 Stavropoulos Objectivity in Law p. 46. Compare Stavropoulos' discussion of the 'act of baptism'; id 25-26.

37 See n 27.
} 
thinks it determines the norm's content. Poetic licence is not something associated with legislative drafting.

The second cost incurred is a blurring of the intuitive distinction between a speaker's meaning and literal meaning. The idea that legislators may mean something that their words do not literally express is a highly plausible one. Yet, if the natural kind literally denoted by a statutory term is fixed to objects legislators regard as exemplars of what they seek to regulate, it would never be the case that legislators intend to regulate a natural kind not denoted by the literal meaning of their adopted terms.

Whatever our theory of a statute's legal meaning, we will occasionally want to differentiate between what legislators meant to regulate and what their legislation literally entails. Unfortunately, Stavropoulos' proposal restricts our ability to make this distinction. Thus, we would like to be able to say of a statute regulating, 'the sale of precious metals', both that its literal meaning entails the regulation of valuable radioactive metals, such as plutonium and uranium, and that its authors had intended just to regulate the sale of valuable non-radioactives such as gold and silver. Plausibly, the legislators regard metals such as gold and silver as exemplars of the natural kind to be regulated. If the statute's literal meaning is the kind of which these metals are exemplars, we could not say that its literal meaning is at odds with the kind legislators intended to regulate, whereas that seems a strong possibility. Certainly, Stavropoulos can say that non-radioactive precious metal is the kind of thing to which the statute properly applies, just as he may say that marine life is the kind of thing to which Munzer's statute applies. The difficulty is that he cannot also say that its terms literally denote certain radioactive metals, such as uranium. But we think that we should be able to do both. As Soames puts it regarding the referential use of descriptions:

[I]n situations in which a description The $F$ is used referentially to pick out an object which is $G$, but which is not in fact $F$, the natural thing to say about a speaker who has uttered $T h e F$ is $G \ldots$ is that although the speaker has said something that is literally false, namely that the $F$ is $G$, he has also said something true, namely that the individual is $\mathrm{G} .{ }^{38}$

We have reviewed three ways in which causal legal semantics might be elaborated to accommodate common intuitions about legal meaning. Each adjustment fell short of that goal. I shall now argue that explaining legal

38 Soames, 'Donnellan's Referential/Attributive Distinction', Philosophical Studies 73 (1994) pp. 149-68, 154 (emphasis in original). 
disagreement as a function of the literal meanings of moral terms requires, but lacks, a causal semantics clearly consistent with the scope of moral disagreement.

\section{Causal Semantics and the Scope of Moral Disagreement}

[W]ith words like 'malice' deference to the legislature does not require that a court abjure from seeking what it elsewhere seeks: the true nature of the thing to which the word refers. That the task here involves moral knowledge is no reason to change the nature of that task. ${ }^{39}$

We noted at the outset that causal legal semantics is motivated by the perceived inability of its conventionalist cousin to account for the scope of legal disagreement. Until now, we have focused on the theory's application to non-moral statutory language. But legal disagreement may also occur over the interpretation of statutes written in moral terms, terms such as 'due', 'cruel' or 'fair'. For proponents of causal legal semantics, such disagreement is a predictable product of moral inquiry into the true nature of the moral kinds causally denoted by such terms. That assumption depends, however, on a story of how a term $t$ may come to causally denote a particular moral kind that clearly accounts for disagreement over what counts as $t$. Without one, the assumption that the reference of moral terms is causally determined cannot explain disagreement over the legal meaning of a statute featuring $t$. In this section, I suggest that we lack such a story.

\section{Paradigmatic Reference-fixing}

The process by which a sound type becomes associated with a meaning is central to semantic theory. CTR's basic account of this process is clear enough; a sound type is associated with a particular kind through a ceremony in which agreed upon objects which share a special sort of similarity relation are dubbed with the type, and in which it is stipulated that other objects will count as instances of the kind if and only if they share that relation. The associated kind becomes (one of) the sound type's meaning(s). There are some well-known difficulties with this account. ${ }^{40}$ But, at least

39 Moore, 'A Natural Law Theory of Legal Interpretation', p. $3^{8} 3$.

40 See $n 13$ above. 
for terms denoting obviously natural kinds like gold or fish, the account is plausibly consistent with the possibility of meaningful disagreement over which objects count as instances. Since the content of the relevant similarity relation may be unknown or misapprehended, we can expect substantive debates as scientists work to identify it. ${ }^{41}$

Although Putnam himself once suggested that one ought, 'to apply a generally causal account of reference also to moral terms, ${ }^{42}$ the process by which their reference may be causally determined remains obscure. Thus, in principle, there could be some set of objects of which all competent speakers would say, 'if anything is an instance of water, these are'. Something similar might plausibly be said of gold and tigers, and so on. Granting this, it seems possible to claim, à la Kripke and Putnam, that the reference of such terms is determined by the shared nature of certain stipulated paradigms.

In contrast, however, it seems open to competent speakers to fail to commonly regard amy action or decision as an example of, say, moral goodness. There is some evidence for this impression in the breadth of contemporary and historical moral disagreement. But the contrast rests not on the breadth of the genuine moral disagreement that has occurred, but on the apparent conceivability of such disagreement with respect to any moral question. That is, it seems that anything offered as paradigmatic of moral goodness might be intelligibly characterized as not morally good. This possibility undermines the idea that the reference of 'moral goodness' may be fixed to paradigm instances of the kind moral goodness just as the reference of 'gold' may be fixed to paradigm instances of the kind gold. For 'moral goodness', competent speakers seem at large to argue over the kind's membership. For natural kind terms, conversely, it seems plausible to suggest that we are in principle ready to recognize objects whose membership may not be intelligibly disputed.

\section{Epistemic Reference-fixing}

Presumably in light of the unavailability of linguistic paradigms for moral terms, no-one has suggested a direct application of the paradigmatic model of reference-fixing to moral vocabulary. Philosophers attracted to causal

${ }^{41}$ See Putnam, 'The Meaning of Meaning', p. 142 (our understanding of what counts as 'water' is defeasible, liable to be revised in light of future investigation).

42 Putnam, Mind, Language, and Reality (Cambridge: Cambridge University Press, 1975) p. 290. 
moral semantics have instead pursued an epistemic theory of referencingfixing. Richard Boyd offers the leading account:

[A] term $t$ refers to a kind (property, relation, etc.) $k$ just in case there exist causal mechanisms whose tendency is to bring it about, over time, that what is predicated of the term $t$ will be approximately true of $k$... Such mechanisms will typically include the existence of procedures which are approximately accurate for recognizing instances of $k$ (at least for easy cases) and which relevantly govern the use of $t \ldots t$ refers to $k$ (in nondegenerate cases) just in case the socially coordinated use of $t$ provides significant epistemic access to $k$, and not to other kinds (properties, etc.) ${ }^{43}$

On an epistemic account of reference-fixing, the term 'evil' refers to the moral kind evil as long as we use procedures to identify evil that are more or less accurate, at least in easy cases, and name what we identify as 'evil' ${ }^{\mathbf{4 4}}$ If such procedures are in place, meaningful disagreement about what 'evil' refers to can be expected: Will this refinement to the procedure for recognizing instances of evil make us more accurate than that refinement? Does this conclusion about what is evil follow from that clear example of evil?, etc.

Disagreement about what principle follows from easy cases of evil can also be accommodated by conventionalist moral semantics. ${ }^{45}$ The distinctive promise of the epistemic theory of reference-fixing is its ability

43 Boyd, 'How To Be a Moral Realist' in Geoffrey Sayre-McCord (ed.), Essays on Moral Realism (Ithaca, NY: Cornell University Press, 1988), pp. 181-228, 195.

44 Terence Horgan and Mark Timmons offer a different gloss, attributing to Boyd a 'Causal regulation thesis: For each moral term $t$ (e.g., "good"), there is a natural property $\mathrm{N}$, such that $\mathrm{N}$ and $\mathrm{N}$ alone causally regulates the use of $t$ by humans'. Horgan \& Timmons, 'Troubles for New Wave Moral Semantics: The “Open Question Argument" Revived', Philosophical Papers 21 (1992), pp. 153-75, 159. Horgan and Timmons' subsequent elaboration of GE Moore's open question argument into a rebuttal of Boyd's account postulates the existence of another human population on a different planet, 'Twin Earthlings', for whom $t$ is causally regulated by a different natural property and with whom Earthlings could have conversations involving $t$ that express genuine moral disagreement. This has led to a digression about whether Putnam's 'Water' Twin Earth and H\&T's 'Moral' Twin Earth are truly analogous; see, e.g.; S. Laurence et al., 'Moral Realism and Twin Earth', Facta Philosophica 1 (1999), pp. $135-65$ (critiquing the analogy); M. Rubin, 'Sound Intuitions on Moral Twin Earth', Philosophical Studies 138 (2008), pp. 307-27 (responding).

45 See, e.g., F. Jackson, From Metaphysics to Ethics: A Defence of Conceptual Analysis (Oxford: Oxford University Press, 1998), pp. 139-62. Jackson's account postulates the possibility of deriving a mature folk morality from critical reflection on current folk beliefs about what counts as 'morally right'. The mature folk morality constitutes 'the best we will do by way of making good sense of the raft of sometimes conflicting intuitions about particular cases and general principles that make up folk morality'; at 133. The natural propert(ies) playing the role which the folk's mature morality attributes to moral rightness determine the meaning of the folk's moral terms. 
to account for the sense that, sometimes, the solutions to disagreements over what counts as 'evil' do not simply follow from an underlying shared criterion as to what counts as 'evil', e.g., from the mature folk morality, but from what evil actually is.

On Boyd's causal semantics, the reference of a moral term $t$ is causally determined by a particular moral kind $k$ if speakers by and large identify $k$ and refer to its instances as ' $t .{ }^{46}$ Unfortunately, the scope of moral disagreement remains a challenge. Imagine two communities, one in which the socially coordinated use of $t$ provides significant epistemic access to $k$, and one in which the socially co-ordinated use of $t$ provides little or no such access. With respect to the moral status of a given action, $t$ as used by a speaker of the former community seems liable to express a meaningful disagreement with speakers of the latter community. The ease with which we can imagine the two sorts of community disagreeing in this way is significant. It suggests that we do not regard the reference of a moral term to be determined by a particular moral kind merely because speakers by and large identify that kind and use the term to refer to its instances. If, as the scenario's credibility suggests, competence with moral terms is not the preserve of those with moral knowledge, how may a community's moral knowledge be thought to determine the reference of its moral terms?

I have just suggested that the leading account of the application of CTR to moral terms struggles to accommodate the scope of moral disagreement. It may be that, on the whole, the relative advantages of a causal moral semantics are such that its difficulty in explaining the scope of moral disagreement is a price worth paying. It is not, however, a price that those seeking a semantics with which to explain the scope of legal disagreement can afford. Until the development of an account which clearly is consistent with moral disagreement, CTR cannot underwrite explanations of legal disagreement as a function of the literal meaning of enacted moral language.

46 Mark van Roojen has recently suggested improving Boyd's account by making it agnostic on the issue of causal determination; van Roojen, 'Knowing Enough to Disagree: A New Response to the Moral Twin Earth Argument', Oxford Studies in Metaethics 1 (2006), pp. 16192. Van Roojen reformulates accordingly; 'If enough people in a community get enough things right about a property, so that in principle there is available to all speakers in a community an epistemic pathway to finding out more about that property, then all members of that community can be credited with thoughts and talk about that property, even if some of what they say is false and even necessarily false.' At 189 . Note that the problem to be identified with Boyd's original account applies equally to van Roojen's version, namely, the failure of moral linguistic competence to correlate with a community's moral knowledge. 
In the final section, I consider the potential contribution of CTR's theoretical apparatus of paradigms and similarity relations to intentionalist explanations of legal practice.

\section{Intended Paradigms and Legal Disagreement}

Legal intentionalism is the theory that the legal meaning of the statute book is primarily a function of its authors' legislative intentions. My aim is not to defend that theory here. I will simply consider whether an appeal to paradigms and similarity relations may account for the scope of legal disagreement more effectively as part of an intentionalist, rather than semantic, legal theory.

The author of a provision might intend that it regulate the kind most naturally unifying certain exemplars. Its legal meaning might accordingly be seen as a function of the similarity relation holding between these intended paradigms, something about which interpreters and legislators themselves may be ignorant. With this hypothesis, the legal intentionalist might hope to account for the possibility of genuine disagreement over the provision's legal meaning. The hypothesis is distinct from Stavropoulos' claim that a provision's legal meaning is a function of its literal meaning as causally determined by legislators' paradigms. Unlike the latter, the intentionalist hypothesis does not require us to adopt an unnatural characterization of legislators as word coiners. Likewise, the hypothesis permits us to distinguish the natural kind which a provision literally denotes from the natural kind to which it is intended to apply. If legislators' exemplars of the kind regulated by a provision appear to bear a similarity relation distinct from that denoted by the term adopted, we may simply say that legislators' use of language was imperfect. Recall our notional 'precious metals' statute. Legislators' paradigms being gold and silver, the natural kind the statute regulates is (precious) non-radioactive metal; but it remains true to say that, given their literal meaning, the provision's terms were ill-chosen.

I argued earlier that the notion of literal meaning as default legal meaning is inconsistent with disagreement over whether something generally accepted as literally denoted by the adopted terms is actually regulated and vice versa. But that notion may be detached from the suggestion, implicit in Soames' discussion of the 'fruit' statute, that legislators may intend to enact a provision's causally determined, 'scientific', literal meaning. Stripped of the requirement that intended departures from literal meaning be 'clear to all', Soames' suggestion coheres with the claim that 
legal meaning is primarily a function of legislative intentions. Likewise, the suggestion is consistent with the possibility of disagreement over a provision's legal application to entities which all agree are, or which all agree are not, literally denoted by its terms. However, though consistent with such disagreement, Soames' suggestion does not provide intentionalism with the resources to explain it. The possibility that legislators might intend to enact a provision's (causally determined) literal meaning does not account for genuine legal disagreement over, say, the extent of the First Amendment's protection of political speech, or over the taking of sea anemone under the 'fish' statute.

Now consider the explanatory power of the hypothesis that a provision's legal meaning may be a function of its author's intention that it regulate the kind most naturally unifying certain exemplars. If interpreters were seeking the shared nature of legislators' intended paradigms of the kind protected, say, that of the pamphleteer and the soap box, or that of whales and sardines, we could expect a meaningful argument over whether their shared natures include corporate political speakers and sea anemone, respectively. The intentionalist might thus characterize a controversy over First Amendment protection for corporate political speakers as one concerning the true nature of the kind of political speaker reflected in the Framers' paradigms ${ }^{47}$ That sort of explanation could not be grounded on the possibility that a provision's literal meaning may be intended, since everyone agrees that the kind of political speaker protected by the Amendment, whatever it is, is not that denoted by its literal meaning. The same applies to our notional controversy over the protection of sea anemone. Insofar as they may explain the scope of legal disagreement, then, the deployment of paradigms and similarity relations in legal theory seems best decoupled from their role in explaining statutes' literal meaning.

A further advantage of an intentionalist exploitation of paradigms and similarity relations is that it permits them to be plausibly applied to provisions written in moral terms. In the last section we argued that CTR cannot underwrite explanations of legal disagreement as a function of the literal meaning of enacted moral language until the development of a causal semantics of moral terms which clearly accommodates moral

47 See, e.g., Reno v. ACLU 521 U.S. 844 (1997), 'Through the use of chat rooms, any person with a phone line can become a town crier with a voice that resonates farther than it could from any soapbox. Through the use of Web pages, mail exploders, and newsgroups, the same individual can become a pamphleteer.' Stevens J, joined by Justices Thomas, Breyer, Souter, Ginsburg, Scalia and Kennedy. 
disagreement. By contrast, the suggestion that legal disagreement is due to the opacity of the similarity relation holding between legislators' paradigms of the kind to be regulated awaits no such development.

Recall our discussion of the challenge facing a paradigmatic account of how the reference of moral terms is fixed. We observed that the moral status of any action offered as a paradigm instance of 'moral goodness' is open to be being intelligibly disputed. In contrast, the extent of disagreement over the legal meaning of a particular provision, even one written in moral terms, is often narrow. Even with respect to statutes whose interpretation is heavily disputed, there is usually a range of interpretive claims that no competent, disinterested interpreter would deny.

We considered earlier the example of the Eighth Amendment, which prohibits the infliction of 'cruel and unusual punishments'. Notwithstanding any legal provision, of course, meaningful disagreement over the morality of punishments such as the thumbscrew is possible. In light of that possibility, use of the thumbscrew seems unavailable as a paradigm to which to fix the literal reference of the word 'cruelty'. Conversely, it seems certain that the authors of the Eighth Amendment intended to prohibit use of the thumbscrew, among other medieval tortures, and that any contrary interpretation would be legally incorrect. ${ }^{48}$ Although merely conventional classifications also have obvious instances, it is plausible that the Framers saw such tortures as paradigmatic of the moral character of the punishments they intended to prohibit. The precise moral character of those paradigms is bound to be a controversial question, one about which everyone, including the Framers, might seem mistaken. The legal intentionalist might thus characterize the interpretation of the Eighth Amendment as a matter of determining the shared moral salience of the Framers' exemplars of the kind of punishment to be prohibited. Genuine disagreement over the constitutionality of, say, capital punishment, could then be expected, notwithstanding the scope of disagreement over what literally counts as 'cruel'.

The point is not that a legal intentionalist appeal to paradigms and similarity relations definitively solves the problem of legal disagreement over provisions written in moral language. It is simply that the appeal is more credible than one which is parasitic on their ability to explain such terms' literal meaning. For agreed paradigms to exist, disagreement must

48 As Ronald Dworkin once put it, 'If the [US Supreme] Court finds that the death penalty is cruel, it must do so on the basis of some principles or groups of principles that unite the death penalty with the thumbscrew and the rack'. Dworkin, 'Special Supplement: The Jurisprudence of Richard Nixon', The New York Review of Books, 4 May 1972. 
be limited in a way that legal disagreement appears to be and in which moral disagreement does not. The legal literalist requires a story of how her semantics accommodates the scope of moral disagreement. The legal intentionalist, by contrast, need only worry about explaining the scope of legal disagreement.

\section{Conclusion}

Explaining the occurrence of meaningful legal disagreement as a function of the causally determined literal meanings of statutory provisions overlooks important features of legal practice. Reflection on Munzer's 'fish' hypothetical suggests that causal legal semantics struggles to explain common intuitions about legal meaning. Equally, reflection on the ability of CTR to account for the scope of moral disagreement suggests that its theoretical apparatus of paradigms and similarity relations might better explain the scope of legal disagreement as part of a traditional intentionalist theory of legal practice. 
Copyright of Journal of Moral Philosophy is the property of Brill Academic Publishers and its content may not be copied or emailed to multiple sites or posted to a listserv without the copyright holder's express written permission. However, users may print, download, or email articles for individual use. 